\title{
Cloranfenicol e identidad
}

\author{
Chloramphenicol and identity
}

Departamento de Medicina Interna Facultad de Medicina, Universidad de Concepción

Correspondencia a: Sergio Mella Montecinos pignatio@vtr.net

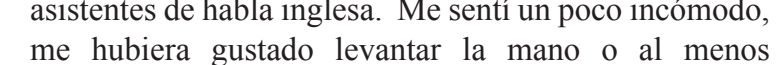

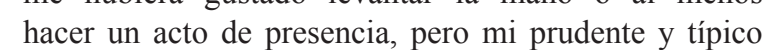
apocamiento chileno me lo impidió, sumado a que a mi alrededor se encontraban auditores más bien rubios o al menos de franco aspecto europeo.

A continuación, el profesor destacó algunas de las propiedades microbiológicas de este antimicrobiano obtenido inicialmente desde Streptomyces venezuelae. Enfatizó su amplio espectro de actividad que incluye aerobios, anaerobios, rickettsias, Chlamydia spp, Mycoplasma spp y espiroquetas. Que a pesar de ser un antimicrobiano fundamentalmente bacteriostático ejercía una acción bactericida sobre aislados susceptibles de Haemophilus influenzae, Streptococcus pneumoniae, Neisseria meningitidis y Bacteroides fragilis.

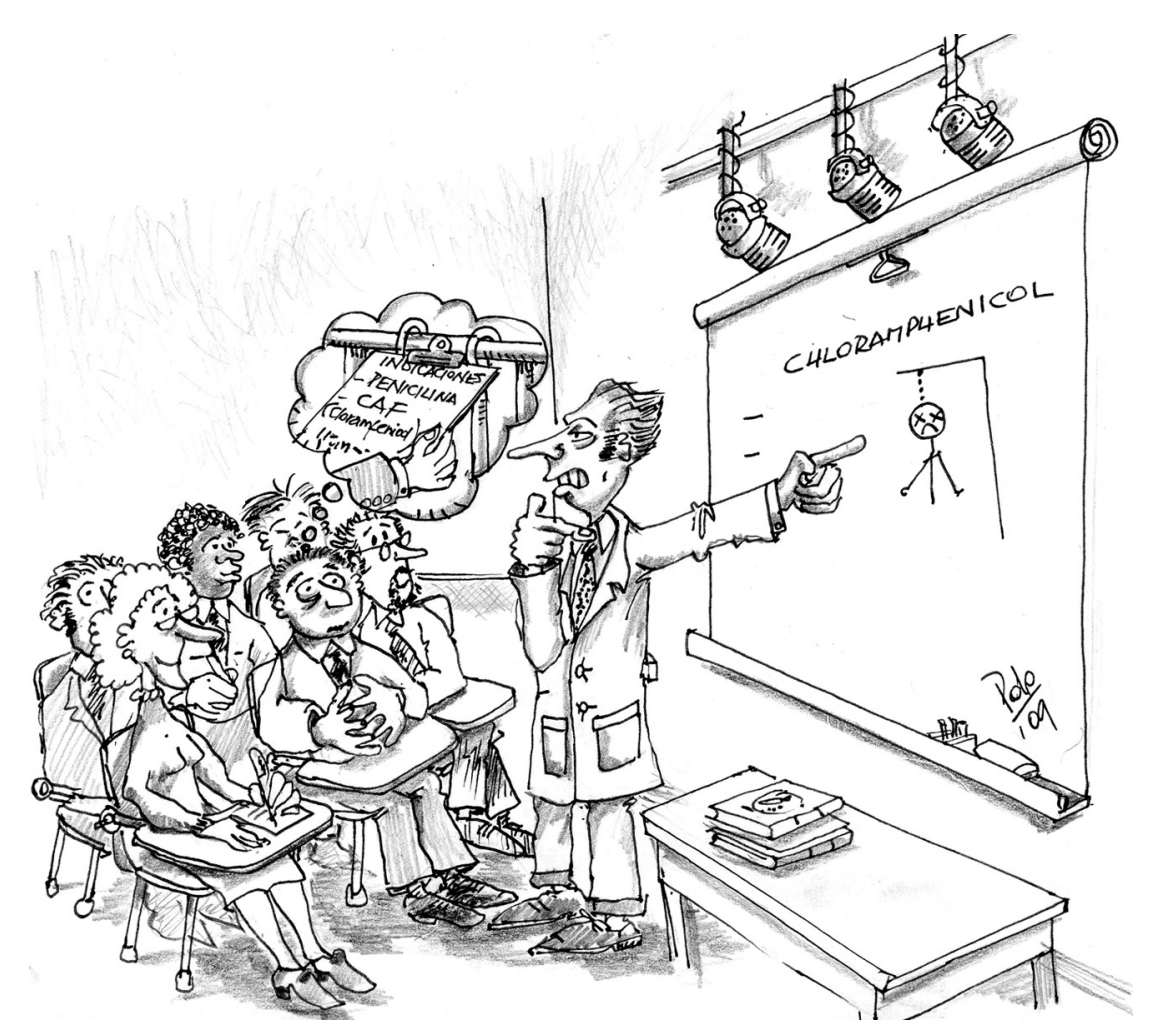

Por otra parte, como buen amanuense de este distinguido profesor, yo intentaba tomar al máximo apuntes en inglés, sin cuestionarme mucho de lo que entendía -no demasiado-y de las diapositivas.

Tengo todavía en mis anotaciones, que esta molécula alcanza elevadas concentraciones en el LCR, entre 30 y $50 \%$ de la concentración plasmática. De hecho, fue antes del descubrimiento de las cefalosporinas de tercera generación un fármaco útil en el tratamiento de meningitis bacteriana aguda (y es todavía alternativa de tratamiento para pacientes con meningitis meningocóccica y alergia a penicilina).

Por otra parte, mencionó la más temida toxicidad de este agente y que explica que sea un agente prácticamente no utilizado en E.U.A. y otros países desarrollados: anemia aplástica, con una frecuencia de 1/25.000 a 1/200.000 pacientes tratados. También recordó otras toxicidades como la medular reversible y el síndrome del niño gris.

A pesar de tomar apuntes en forma automática, la información que entregaba el expositor no era desconocida para mí; de hecho fueron enfatizadas con fuerza en Ciencias Básicas en el pregrado de la carrera de Medicina, ya sea en Farmacología o Microbiología.

Sí era nuevo para mi saber que en E.U.A. no se vendía la forma oral de este medicamento y que la FDA lo aprobaba para su uso en infecciones producidas por los microorganismos antes descritos cuando no había otras alternativas terapéuticas, o sea: no se utilizaba.

Pero ¿era yo un típico médico americano que ejercía en un hospital medio de este gran país?, la realidad es que yo venía de las antípodas y que el paciente medio del cual soy responsable no es descendiente de WASP (blanco, anglosajón y protestante) ${ }^{1}$ no habla inglés $y$, categóricamente, en promedio es moreno, de pelo negro, bajo, de apellidos españoles y/o mapuches y habla, como dijo con genialidad Roberto Bolaño ${ }^{2}$, algo parecido al español. Somos por tanto en esencia - tal como lo señaló un español por antonomasia como Leopoldo Castedo- producto de la mezcla entre genes peninsulares y de nuestra población autóctona ${ }^{3}$.

Es por tanto, la diferente constitución racial de nuestro pueblo la que explica la escasa descripción de toxicidad hematológica en nuestro país.

Más aún, en países como Chile existe una amplia experiencia con este agente en el tratamiento de fiebre entérica ${ }^{4} \mathrm{y}$ en otras infecciones incluyendo infecciones polimicrobianas y mixtas, asociado por ejemplo, a penicilina 
y gentamicina; más aún recordé la rotación en el hospital de Enfermedades Infecciosas Dr. Lucio Córdova cuando realizaba mi beca de Infectología, donde me confirmaron la amplia experiencia en el uso de cloranfenicol y la escasa sino nula descripción de aplasia medular.

Pero el problema fundamental que quiero plantear, se me hizo patente tiempo después cuando un grupo de niños andaba disfrazado y quería algún caramelo mientras celebraba Halloween (tampoco de celtas o irlandeses tenemos mucho). Cómo puedo compatibilizar la admiración que siento por instituciones y conceptos tan propiamente norteamericanos que van desde el self made man, pasando por la capacidad de trabajo en equipo hasta la libertad de expresión ${ }^{1,5}$ y su influencia en nuestras actividades cotidianas y profesionales con lo que uno es, un chileno, un médico chileno que desarrolla su proyecto vital en nuestro país, con sus luces y sombras por todos conocidas.

La respuesta obviamente es a la vez simple y compleja, mantener el equilibrio. Para esto debemos mantenernos integrados con el mundo, pero con nuestros pies firmemente asentados en esta larga faja; dependerá de la inteligencia y prudencia con la cual apliquemos y adaptemos lo que aprendemos del mundo y particularmente de E.U.A., del éxito que tengamos no sólo en Medicina, sino también en nuestro proyecto de país.

Por ahora a los alumnos de pre y post grado de mi Universidad les enfatizó que nosotros todavía podemos utilizar el cloranfenicol, que los aislados de Salmonella enterica subs. enterica serotipo Typhi de nuestro medio siguen siendo susceptibles a este antimicrobiano; que posee una adecuada actividad anti-anaeróbica y que asociado a gentamicina (con o sin penicilina G) constituye un esquema comparable a otras asociaciones de antimicrobianos para el tratamiento de infecciones polimicrobianas y mixtas.

Sergio Mella M.

Servicio de Medicina Interna

Hospital Regional Guillermo Grant Benavente

Concepción, Chile

\section{Referencias}

1.- Huntington SM. Who are we? The challenges to America's national identity. Simon \& Schuster paperbacks, New York, USA 2005.

2.- Bolaño R. El secreto del mal. Editorial Anagrama, Barcelona, España, 2007.

3.- Castedo L. Contramemorias de un transterrado. Fondo de Cultura Económica, Santiago, Chile, 1997.

4.- Kraljevic R. Recuerdos de un viejo infectólogo, Santiago, Chile, 1998.

5.- Johnson P. Estados Unidos, la historia. Javier Vergara Editor, Barcelona, España, 2002. 